COST AND QUALITY

\title{
Quality or financing: what drives design of the health care system?
}

\author{
V McLoughlin, S Leatherman
}

Qual Saf Health Care 2003;12:136-142

The scope and scale of problems in the quality of health service provision have been increasingly recognised in recent years. Policy and planning for financing are usually concerned with how funding is made available and allocated, rather than with what is being achieved, including the quality of health services delivered. A fundamental challenge is how to improve the delivery of health services to achieve improved patient outcomes and to optimize financial outcomes. To accomplish this it is essential that the debates on quality of care and financing are aligned. Approaches to improving the quality of care are drawn from Australia, the US, and the UK. Financing arrangments for care at a national level have a bearing on how payment incentives can be used to promote or impede quality. The level of overall expenditure is obviously important, as are the mechanisms for payment. Long term programs to build knowledge, standardise processes, provide credible performance data and foster accountability are required to ensure that further investments lead to improvement in care.

See end of article for authors' affiliations

Correspondence to:

Correspondence to:
Dr V McLoughlin, MDP 46, GPO Box 9848, Canberra ACT 2601, Australia; vin.mcloughlin@health.gov.au

Accepted for publication 29 December 2002
T he sustainable financing and quality of care agendas share the same principal objective of maximising the benefit for the resources expended in a predictable and sustainable mode. Yet the nature of the debate is different.

Traditionally, the financing debate has focused on issues of "how" revenue and expenditure are managed, with particular attention to affordability and efficiency. The fundamental need is to ensure that overall levels of expenditure on health are sufficient to provide the infrastructure necessary for health services-such as medicines, equipment, facilities and providers - to the entire eligible population. However, once this threshold is achieved, the mechanisms through which payments for specific services are made can be an important determinant of how and what type of care is provided. Yet these payment mechanisms are rarely specifically designed to achieve explicit clinical care or patient outcome objectives.

The quality debate is primarily about "what" processes should be used and what outcomes should be achieved or, in financial terms, how to maximise return on investment. This necessitates the development of a clinical evidence base and adherence of practice to what is known or believed to be appropriate and effective care.
There are a number of reasons for exploring the relationship between quality improvement and sustainable financing. In particular, studies of future trends in health care indicate that the provision of care will become more complex and the demands on the system will increase over time. This means that the best use of existing and new resources must be assured.

Poor quality care generates unnecessary costs through the underuse, overuse, and misuse of interventions and services. Moreover, quality improvements will not automatically flow either from the good intentions or training of healthcare professionals. Good quality outcomes are increasingly related to how processes for ongoing quality improvement are built into systems design.

This paper brings together the "what" and the "how" of the health financing debate to explore how they can be aligned to improve value. It defines quality in health care and presents data on the scope, breadth and cost of quality of care problems in the UK, USA and Australia, with brief summaries of current national strategies. Aspects of the debates about health financing are drawn together with reference to how they may impact on quality. Finally, a parallel process of investment with reform programmes is suggested.

\section{DEFINING AND DESCRIBING QUALITY IN HEALTH CARE}

The term "quality" is used in this paper in the sense defined by the Institute of Medicine: "the degree to which health services for individuals and populations increase the likelihood of desired health outcomes and are consistent with current professional knowledge." ${ }^{2}$ Quality is therefore both a relative and an empirically based term, involving elements of judgement in its assessment and uncertainties both in knowledge and practice.

Efforts to improve and monitor performance have led to the identification of a number of domains of quality. Within national (Australia, US, UK, Canada, and New Zealand) and international (WHO and OECD) initiatives, consensus is emerging that quality involves the following domains: safety, effectiveness, appropriateness, responsiveness/patient centred care, equity/ access, and efficiency. ${ }^{3}$ Other attributes of any healthcare system such as overall capacity and technological capability also affect these outcomes. Quality of care efforts must focus at both the macro (population) and micro (individual) levels. While the ultimate test of healthcare systems may be their impact on health outcomes at the population level, many population level health outcomes are more susceptible to nonmedical factors such as sanitation, education and housing than to the influence of healthcare services. ${ }^{4}$ 
Historically, quality in health care has been an implicit judgement at the level of patient-physician contact. Quality has been largely addressed through professional registration, review of professional appointments, and less formal peer review processes. Over the last two decades this has changed dramatically, with increasing recognition that quality improvement cannot be seen just as a byproduct of other processes.

Problems with timely access to treatments-for example, in the UK-and the equitable distribution of care-for example, in the US-are well documented, although they are distributed differently across countries. Access and equity are critical to quality, as well as safety, effectiveness, and appropriateness which are the focus of this paper.

\section{SCOPE AND SCALE OF PROBLEMS WITH QUALITY Stakeholder perceptions of quality}

Numerous surveys, both in individual countries and comparisons between countries, portray the formidable scale and scope of performance issues. Whether through the eyes of physicians, patients or purchasers/payers, concerns regarding eroding performance are widespread. In a survey conducted in Australia, New Zealand, Canada, the UK, and the US, physicians reported a significant decline in their ability to deliver high quality care in all five countries. ${ }^{5}$ When asked how their ability to provide quality care had changed over the past 5 years, a significant number of physicians reported that it was worse (Australia 38\%, Canada 59\%, New Zealand 53\%, UK $46 \%$, US $57 \%$ ). Only one quarter or less of the physicians in any country reported that their ability to provide high quality care had improved over the past 5 years. This finding is supported in another recent survey in which $17-44 \%$ of nurses in five countries (Canada, Germany, Scotland, England and the US) reported that quality had deteriorated in the past year. $^{5}$

Although it is tempting to discount these findings as complaints by disgruntled clinicians, we also need to look at public perceptions of the performance of health systems. In a survey of attitudes of both the public and physicians in Australia, UK, USA, Canada, and New Zealand performed in 1998, the public indicated overwhelmingly that the health system in their country required fundamental change or a complete overhaul. ${ }^{5}$ In fact, the level of dissatisfaction was dramatically revealed in a 1998 American Consumer Satisfaction Index which placed hospitals between the US Postal Office and the Internal Revenue Service. ${ }^{6}$ This sobering assessment clearly indicates a mistrust of the American public in health care institutions and provides one more dramatic data point to illustrate the pressing need to address performance issues.

\section{Safety and medical error}

The US, UK and Australia have each recently experienced growing concerns about medical errors and a heightened emphasis on safety and quality. In the US the Institute of Medicine Report "To Err is Human" estimated the incidence of mortality relating to medical error to be $44000-98000$ per year. ${ }^{7}$ In Australia the Quality in Australian Health Care Study reported on a study of over 14000 medical records which found that $16.6 \%$ of hospital admissions were associated with an adverse event. ${ }^{8}$ In the UK recent failures in medical careBristol and Newham-have reinforced a growing public anxiety regarding the safety of medical care which has resulted in a number of new initiatives outlined in the Chief Medical Officer's publication "An Organisation with a Memory". "

This area of safety illustrates the inherent mutuality of interest between the quality and financing agendas. Extrapolating the US and Australian experience to the UK, the more conservative (American) findings suggested that over 300000 adverse events per annum are associated with a cost of over $£ 1$ billion. Recently, the National Audit Office in England reported that the outstanding claims for alleged clinical negligence in NHS hospitals totalled $£ 3.9$ billion (\$US5.6 billion). Medical error, or safety deficiencies, constitutes a major risk for the sustainability of financing.

\section{Effectiveness and appropriateness}

In the USA, studies published in leading professional journals consistently report that people with acute and chronic medical conditions receive only about two thirds of the health care needed and, at the same time, that $20-30 \%$ of interventions are either unnecessary or of questionable benefit. ${ }^{10}$ Significant variations in the use of specific healthcare interventions have long been observed and raise questions about the effectiveness of care for common conditions. Some treatments continue to be used despite strong evidence that they may be ineffective or even harmful-for example, the use of antibiotics for upper respiratory infections or enforced bed rest in pregnancy. ${ }^{11}$ Numerous interventions known to be effective are underused-for example, $\beta$ blockers to prevent recurrent heart attacks and warfarin for atrial fibrillation.

\section{IDENTIFYING STRATEGIES TO ADDRESS THE PROBLEMS}

As dramatic as these quality problems are collectively, projections indicate that they are likely to grow. The pressures on the healthcare system are likely to increase with the growth in the aging population, increasing public expectations, and continuing gaps between demand and capacity. ${ }^{12}$ A sluggish response on the part of the health services sector is predictable because of the conservative nature of workforce development strategies and the inertia of large complex and hierarchical institutions (such as hospitals). The complexity and scale of the health services sector will inevitably exacerbate the challenges further. ${ }^{13}$

There are two major categories of problems in qualitythose at the systemic level and those at the individual provider level. Attempting to address problems at either level alone will not be successful. Multiple strategies for remediation must be employed to ameliorate performance deficiencies. Three key strategies are:

- improving processes and standardisation at the system level;

- knowledge enhancement at the individual provider level; and

- patient engagement.

\section{Improving processes and standardisation at the system level}

To identify appropriate ways of improving performance in the healthcare sector it is useful to consider other "high risk, high reliability" business sectors such as military operations, mining, space travel, and aviation. Each of these has moved towards higher performance in terms of safety. Amalberti has identified a "migration path" for improvement that requires the articulation of knowledge about what works, the standardisation of procedures, and the improvement of human and organisational factors. ${ }^{14}{ }^{15}$ Figure 1 illustrates this migration path, drawing on an analysis of concepts derived from error reduction strategies in aviation.

Over a period of time, systems need to move through an initial phase of developing knowledge about what works and what does not, which Amalberti refers to as the "heroic time". During this phase many errors and injuries occur. The next phase, referred to as the "business and technical time", involves standardisation of processes. This occurs through changes in many performance shaping factors. This is the point at which most of the gains are made in safety improvement. To achieve the greatest safety levels the system has to be designed to correct human error and organisational problems. 


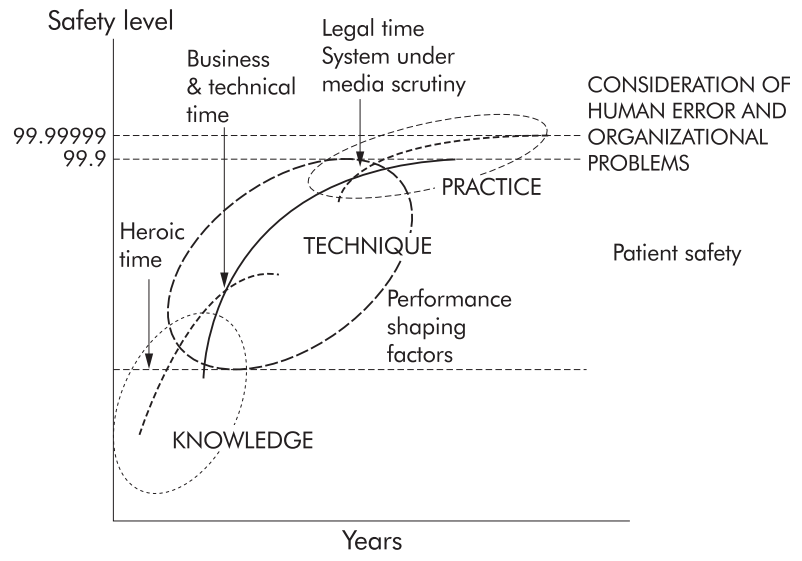

Figure 1 How a system becomes safe.

Despite the differences between the aviation and health sectors, a comparison of the approaches has been useful in showing that the problems in health care are also largely systemic - that is, many of the failures relate to the organisational features of care rather than the acts of individual carers failing in their duties. These flaws can be "designed out" of the system of care, but this represents quite new thinking in health-substantially moving the focus of attention away from the individual clinician's behaviour towards environmental issues, equipment deficiencies, and the functioning of the clinical teams. As discussed in more detail below, funding and payment issues are a major factor in addressing system level performance.

\section{Knowledge enhancement at the individual provider level}

Knowledge deficiencies may be best understood as simply deriving from an inability to master new knowledge at the rate and complexity it is being produced. Even well intentioned and highly motivated clinicians have to grapple with the volume of evidence that is constantly becoming available. In three decades (mid 1960s to mid 1990s) the number of randomised clinical trials published increased from 100 to 10000 articles annually. In the past 5 years alone, nearly half $(49 \%)$ of all the extant medical literature has been published. ${ }^{16}$ This knowledge gap results in a knowledge lagthat is, the time lapse between identification of more efficacious treatments and their incorporation into routine practice. This time lag has been estimated to be in the range of 15-20 years, and even then the adoption of evidence into practice is very uneven. ${ }^{17}$ The challenge of translating research into practice is not only manifest in complicated clinical conditions or the use of emerging technologies and pharmaceuticals, but also in the most routine medical problems such as the common cold, for which physicians prescribe antibiotics in $40-60 \%$ of outpatient visits even though there is no evidence that antibiotics are effective. ${ }^{18-20}$

In terms of the degree of uncertainty about what works, there are many healthcare procedures and tests that have marginal or no proven benefit. ${ }^{21}$ Even when an intervention is proved by randomised controlled trials to be effective, the skills of the provider may lead to a significantly poorer outcome for patients. ${ }^{22}$

How do these knowledge and proficiency gaps affect sustainable financing? The cost implications are huge-one example is the use of cardiac invasive procedures. In the US, researchers from RAND found that, in one state, $50 \%$ of coronary angiographies were performed so incompetently as to render them inaccurate for diagnostic interpretation. If extrapolated to all 1.3 million angiographies performed in the US in 1998, the $50 \%$ error rate would cost approximately US $\$ 8$ billion. $^{23}$
A serious challenge exists to rectify this problem of knowledge deficiency, particularly when understood as a continuous need for facilitating rapid uptake of published evidence into daily patient care. There are a number of processes necessary to synthesise and assess the available evidence and to translate this evidence into practice. Figure 2 shows some of these steps.

Applying evidence of effectiveness to standardise practice Processes of performance review and public reporting are important strategies to increase evidence-based medicine and achieve more standardised practice (fig 2). Performance indicators embedded in guidelines and protocols at a level understandable and actionable by clinicians are widely used to facilitate translation of evidence into routine practice. Physicians can more easily digest performance measures as they are often produced in a simple format defining critical process or outcome measures. However, there are significant challenges in the use of performance indicators to guide practice, and the acceptance of protocols and guidelines by physicians is likely to differ from country to country.

The development of clinical guidelines and protocols is a necessary but not sufficient condition. Published research to date has not shown that the use of clinical guidelines and protocols alone has been effective in changing physician behaviour. ${ }^{10}{ }^{24-27}$ In the UK a recent BMA survey of more than 100 doctors found that $70 \%$ did not believe that the newly established national body (National Institute for Clinical Evidence) which is developing the evidence basis for guidelines and protocols is acting independently. Furthermore, 75\% said they disagreed with at least one of the newly developed decisions and $85 \%$ said that they would ignore the Institute's guidance if they thought it was wrong. ${ }^{28}$

More broadly, the literature documents few systematic improvements using only data feedback by hospital or medical groups. Although there are some notable exceptions, most have had rather modest improvements, arguing that additional interventions should be used in a complementary way to modify provider behaviour. ${ }^{29}$ The importance of payment design once again argues for the need of aligning the financing and quality agendas.

\section{Engaging patients and consumers}

During the past 2-3 years improving patients' experience of health care has become a higher and more visible priority across North America, Australia, and Europe. Quality from a patient's point of view relates not only to outcomes but also to humane respectful treatment, convenience, and timely access. Yet physicians often believe that quality should be based more on what is done to patients than what happened to them and how it happened. ${ }^{2}$

There are two applications of performance indicators at the level of the individual citizen: (1) as a potential consumer of services and (2) as a patient. In the first there are increasing efforts by governments to define the healthcare system as a public service with the citizen as a consumer having rights and responsibilities. In the UK this has taken the form of articulating the modernisation programmes for the "new NHS" using language of "a health service designed around the patient". Newly committed resources and initiatives to promote citizen and patient empowerment include making information more readily available by free telephone calls to nurses and an electronic medical library providing access for the consumer to medical information shared with the clinical professionals. ${ }^{30}$ Programmes to empower patients are not just politically correct, they can be effective at rationalising resources. There is now a body of literature documenting the salutary effects of giving information to patients who have better outcomes, choose less risky procedures, and avoid equivocal treatments. ${ }^{30}$ 


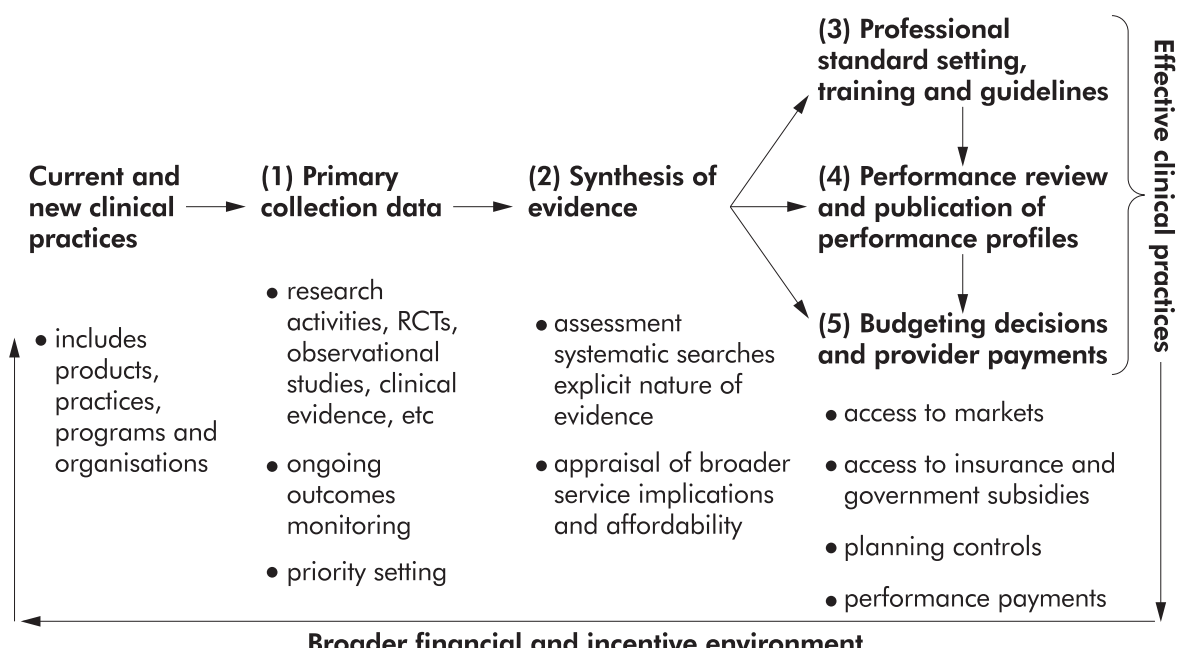

Figure 2 Steps in assessing, appraising, and applying evidence of effectiveness.

However, evidence to date would suggest that, on their own, formalised approaches to continuous quality improvement including patient engagement have not had an impact on healthcare processes commensurate with their impact on critical processes in other industries. ${ }^{31}$ The effective transfer of concepts of quality improvement from broader industry to health care is not straightforward and knowledge of how to use such tools most effectively to improve quality within health care is still limited.

\section{CHALLENGES AND STRATEGIES FOR EFFECTIVE ACTION}

Table 1 presents some of the challenges and strategies for effective action to move towards a safe and high quality healthcare sector, including payment mechanisms. Notwithstanding the many challenges, focusing on organisations and systems of care has the obvious appeal of pragmatism given the daunting challenges of dealing with every individual provider directly. In addition, there is evidence that organisation/ systems of providers use data to change care processes, improve responsiveness to patient feedback, and act to ameliorate circumstances associated with the occurrence of adverse events. ${ }^{32}$ But the outcomes are patchy across the system. Leatherman and Sutherland ${ }^{33}$ commented that, in the UK, the knowledge generated from quality improvement activities at the organisational level has been important but has not led to predictable systemic change. It is also increasingly apparent that investments in quality information systems are necessary to effect and sustain change successfully at either the system or individual level. ${ }^{34}$ These factors argue for the implementation of a broad strategy using multiple methods of quality improvement.

\section{HOW DO FINANCING STRUCTURES IMPACT ON QUALITY?}

We have explored the nature of quality problems and some of the most commonly used approaches to improve care. Improvement strategies must also include the intentional design of payment mechanisms and use of financial incentives. A discussion of issues related payment and incentives must first consider current financing systems, their structure and funding levels. Four major aspects will be discussed here:

- the overall level of resourcing available;

- the structure of health financing (the way funds are raised and disbursed);

- the major payment mechanisms; and

- the specific use of incentives.

\section{Structure and levels of financing}

The fundamental differences in organisation and financing in Australia, the UK, and USA provide a unique opportunity to analyse different approaches to performance improvement. At one end of the continuum is the UK which has a nationalised, centrally driven healthcare system. The UK has had a lower spending rate on health than most other OECD countries, but the UK government has recently initiated a bold set of reforms linking performance goals with a variety of financing and governance incentives. In sharp contrast to the monolithic structure of the NHS in the UK, US health care is a concatenation of healthcare systems with variable insurance benefits, influenced by differing regulation at a combination of state and federal levels. It is a pluralistic private sector dominated health system with a market based approach where price competition has often driven selection and choice, although quality indicators are increasingly used by healthcare purchasers and consumers to catalyse performance improvement. Australia stands between these two approaches and represents a unique blend of features seen in the US and UK. It has an established universal access system, complemented by the use of market like financing incentives and stimulation of the private sector. This has accelerated over recent years. About $31 \%$ of health expenditure is private spending. The key features of the healthcare financing systems in these three countries are summarised in table 2 .

As shown in table 2, there are significant differences between the countries in the level of health expenditure as a percentage of gross domestic product (GDP). One of the strongest predictors of the proportion of GDP spent on health care by western nations is the size of the GDP itself. ${ }^{35}$ This, together with pharmaceuticals and technology which are the known strongest drivers of spending, indicate that increased spending on health care is inevitable in western nations. Clearly, spending below a threshold level of GDP will result in suboptimal care as the capacity for patients to access drugs and medical care will be severely constrained. However, it is also clear that many OECD countries have reached a plateau where it is difficult to demonstrate any great improvements in care in relation to greater investment. The US already spends more on health as a percentage of GDP than any other nation but there is no conclusive evidence that health outcomes or services are better. ${ }^{36}$

\section{Payment mechanisms and incentives}

It is beyond the scope of this paper to comment on the macro issues related to how funds are raised and disbursed. Payment mechanisms have been linked more directly to quality of care. 
Table 1 Attributes of a sector to provide high quality health care

\begin{tabular}{|c|c|}
\hline Challenges & Strategies \\
\hline $\begin{array}{l}\text { Enhancing knowledge } \\
\text { - Rigorous evidence in limited specific areas } \\
\text { - Systematic assessment of learning what works in practice } \\
\text { - Integrated patient perspective }\end{array}$ & $\begin{array}{l}\text { - Research driven more by questions of improved outcomes for patients } \\
\text { - Techniques to appraise, organise and make accessible available evidence } \\
\text { - Capacity to pool and monitor local data including patient views in areas } \\
\text { that require intervention } \\
\text { - Point of care computers that support rapid access to patient data, tests } \\
\text { and evidence }\end{array}$ \\
\hline $\begin{array}{l}\text { Standardising processes (consistent application of practices known to be } \\
\text { - Differences in service configurations at local level } \\
\text { - Uneven resourcing at local level } \\
\text { - Predominance of apprenticeship learning } \\
\text { - Tensions between professional autonomy and public accountability }\end{array}$ & $\begin{array}{l}\text { - Development of standards and protocols based on evidence where } \\
\text { possible } \\
\text { - Decision support systems widely distributed at clinical encounter level } \\
\text { - Training and education that recognises practical barriers to } \\
\text { implementation } \\
\text { - Performance review at a local level by the multidisciplinary teams and by } \\
\text { - Professional peers } \\
\text { - Personal incentives, both professional and financial (including the removal } \\
\text { - Public reporting with adequate interpretation of issues } \\
\text { - Automated communication processes }\end{array}$ \\
\hline $\begin{array}{l}\text { Increasing effectiveness and predictability of performance at system level } \\
\text { - Infinite demand } \\
\text { - Hierarchical and feudal relationships } \\
\text { - Low level of investment in work process design and review }\end{array}$ & $\begin{array}{l}\text { - Clear operating values that appropriately balance capacity with the } \\
\text { objectives of effectiveness, efficiency and equity } \\
\text { - Capacity for shared performance review } \\
\text { - Incentives that foster adoption of best practices and remove barriers of } \\
\text { blame, cost and lack of resources } \\
\text { - Long term funding stability that allows local level sustainable investment in } \\
\text { service redesign }\end{array}$ \\
\hline
\end{tabular}

Over the last three decades there have been many efforts to influence practice in all three countries by the use of purchasing or contracting incentives and different forms of payment and reimbursement. These involve paying for the number of people registered for care by particular practitioners (capitation); capped or global budgets for hospitals or healthcare networks; payments targeted at particular outcomes (incentives payments); fee-for-service or per episode of care. These have mainly focused on increasing throughput (for example, increased numbers of admissions in the UK), improving productivity (for example, decreased average lengths of stay in hospitals), and rewarding appropriateness (for example, increasing preventive care and reducing unnecessary care).

Pay for performance is a concept of growing interest in both publicly financed and private payment healthcare systems. Evidence indicates that payment policies can strongly influence how both the institutional provider (hospitals, health systems) and individual providers (physicians and healthcare professionals) provide health services. ${ }^{37}$ Designing and implementing funding mechanisms to reduce suboptimisation in care is therefore vital. There is some evidence to indicate that certain payment mechanisms are associated with particular practicesfor example, capitation with providing fewer services and fee-for-service in encouraging the provision of more services; however, only very limited research is available on the use of payment for objectively measured performance.

Paying for results or rewarding high quality of care is not a new concept. It has been applied in various countries to promote preventive services such as immunisation. For years GPs in the NHS have been paid additionally for reaching target rates of immunisations. In Australia incentives have included cash to parents and doctors to encourage immunisations, and in the US various experiments have been made with payment mechanisms to reward reduction of unnecessary procedures while reinforcing primary prevention. It is prudent, however, that financing incentives be used only when there is strong evidence of effectiveness and specific outcomes

Table 2 Comparison of features of the health financing systems of the USA, UK and Australia ${ }^{35}$

\begin{tabular}{|c|c|c|c|}
\hline Features of health financing & USA & Australia & UK \\
\hline$\%$ GDP on health expenditure & $12.9 \%$ & $8.6 \%$ & $6.8 \%$ \\
\hline$\%$ public $v$ private & $44.8 \%$ & $70 \%$ & $83 \%$ \\
\hline Insurance payment mechanisms & Employer related insurance & $\begin{array}{l}\text { Private insurance with tax rebates; } \\
\text { universal tax payments }\end{array}$ & $\begin{array}{l}\text { Universal tax based insurance } \\
\text { scheme }\end{array}$ \\
\hline Hospitals/networks payment mechanisms & Volume related payments & $\begin{array}{l}\text { Global budget and some volume } \\
\text { related }\end{array}$ & $\begin{array}{l}\text { Global budgets through areas } \\
\text { with performance pay }\end{array}$ \\
\hline $\begin{array}{l}\text { Practising medical practitioners per } 1000 \\
\text { population (late 1990s) }\end{array}$ & 2.7 & 2.5 & 1.8 \\
\hline $\begin{array}{l}\text { Community physicians/GPs payment } \\
\text { mechanisms }\end{array}$ & $\begin{array}{l}\text { Through private insurance: fee for } \\
\text { service or sessional with incentives }\end{array}$ & $\begin{array}{l}\text { National fee for service with some } \\
\text { practice related payments }\end{array}$ & $\begin{array}{l}\text { Capitation and practice payments } \\
\text { with incentives }\end{array}$ \\
\hline $\begin{array}{l}\text { Nurses and allied health payment } \\
\text { mechanisms }\end{array}$ & $\begin{array}{l}\text { Through insurance cover mainly } \\
\text { with safety net }\end{array}$ & $\begin{array}{l}\text { Through public hospitals and specific } \\
\text { programs; otherwise private payments }\end{array}$ & Through public hospitals and GPs \\
\hline $\begin{array}{l}\% \text { Total health expenditure on } \\
\text { pharmaceuticals }\end{array}$ & $10.1 \%$ & $11.4 \%$ & $16.3 \%$ \\
\hline Pharmaceuticals payment mechanisms & Through private insurance & $\begin{array}{l}\text { Public subsidy on basis of cost } \\
\text { effectiveness with co-payments }\end{array}$ & Mainly publicly subsidised \\
\hline
\end{tabular}


can be articulated. This will limit their application to targeted areas of quality improvement.

A second major task for the rational design and implementation of incentives is removal of financial barriers to improving care. The judicious use of financial incentives requires careful design in two ways: (1) reinforcing positive performance through additional payments, and (2) removing payment mechanisms that perversely affect desired performance. For example, if a performance target is identified for the reduction of unnecessary hysterectomies, the payment methods must, at minimum, eliminate the financial barrier to performance that results in a loss of income for those hospitals most successful at achieving the target. In the case of reducing unnecessary procedures, a fee-for-service hospital funding method results in a reward to the payer rather than to the unit responsible for the performance objective-that is, the hospital-which incurs a loss of income.

Financial incentives may be reinforced by non-financial rewards. A new incentive system being implemented in the UK will reward high performers with greater institutional autonomy, including financial management, while the lower performers will be required to demonstrate intent to change and be subjected to more external vigilance. Judgements of performance will be based on the explicit performance indicators developed as part of a major national initiative called the National Performance Framework, as well as being overseen by an independent external review body (the Commission for Health Improvement). ${ }^{38}$

\section{SUMMARY: THE IMPERATIVE TO JOIN UP THE FINANCING AND QUALITY AGENDAS}

The healthcare systems in the countries described here face similar dilemmas: rising patient expectations, growing evidence of quality of care problems, pressures for increased spending (as a percentage of GDP), constant enhancements to technological capacity, and disparities in ethnic, race and sex groupings.

Being a service sector, the capacity to manage these pressures is determined by those who provide these services and those who provide funding. Harm is occurring to patients at unacceptable levels, yet there is little dialogue about how reducing patient harm and increasing the effectiveness and value of services can contribute to managing these financial pressures. This is partly because of the lack of clarity about the critical attributes of a high quality, safe healthcare system. Even where it is recognised that more funding is needed, the development of financing mechanisms has not focused greatly on improving effectiveness, partly because of its complexity.

There are significant challenges in the use of financial incentives to improve care predictably. Firstly, the state of the art is embryonic - that is, there is an insufficient evidence base for understanding what works, under what circumstances, and with what intended and unintended consequences. Secondly, the costs—both direct and indirect—are daunting, particularly in developing the necessary information infrastructure which is deficient in many countries, particularly in the area of informatics competencies. Thirdly, the complexity of the healthcare sector and the multiplicity of "audiences and actors" means that there are likely to be both intended and unintended consequences of any approach.

Recognising the inherent limitations of any one method or strategy implies the need to use a blend of approaches with complementary effects. The use of financial incentives as an intervention requires the concurrent use of performance indicators to create intentional change in healthcare systems and to minimise the inevitable occurrence of untoward consequences. Governments will need to consider providing resources not only for the collection and analysis of data, but also for the extensive investment in process redesign and workforce training development.

\section{Key messages}

- There are significant problems with the quality of health care in Australia, the USA, and the UK, among other countries

- This is reflected in the perceptions of stakeholders, in unintentional harm to patients, overuse of ineffective care, and underuse of effective interventions.

- Poor quality generates additional costs, yet current financing arrangements may actually impede improvements in care.

- Financing issues are usually debated in terms of the level and method of funding without clarity about what needs to be achieved to address quality of care.

- Achieving improvements requires attention to stable investment in knowledge management, standardising processes of care, and the redesign of organisational features.

Discussions of funding levels will be ubiquitous and incessant. However, this commentary would suggest that it is critically important to focus on systems of funding and payment that can provide the capacity and motivation to improve performance in real time, while adapting financing strategies to meet the changing demands on the health sector in the long term.

\section{Authors' affiliations}

V McLoughlin, Priorities and Quality Branch, Health Industry and Investment, Department of Health and Ageing, Australia

S Leatherman, School of Public Health, University of North Carolina, USA and Judge Institute, University of Cambridge, UK

\section{REFERENCES}

1 Berwick D. Taking action to improve safety: how to increase the odds of success. Keynote address to the Enhancing Patient Safety and Reducing Errors in Health Care Conference, Annenberg Center for Health Sciences, 1998

2 Institute of Medicine. Medicare: a strategy for quality assurance. Lohr $\mathrm{KN}$, ed. Volumes I and II. Washington, DC: National Academy Press, 1990.

3 Anderson G, Hussey PS. Comparing health system performance in OECD countries. Health Aff $2001 ; 20: 219-32$

4 World Health Organisation. The World Health Report 2000. Health systems: improving performance. Geneva: World Health Organisation, 2000

5 Blendon RJ, Schoen C, Donelan K, et al. Physicians' view on quality of care: a five country comparison. Health Aff 2001;20:233-43

6 Lieber RB, Grant L, Martin J. Now are you satisfied? The 1998 American customer satisfaction index. Fortune 1998;137:161-8.

7 Institute of Medicine. To err is human. Washington DC: National Academy Press, 2000

8 Wilson R McL, Runciman WB, Gibberd RW, et al. The quality in Australian health care study. Med J Aust 1995;163:458-71.

9 Department of Health. An organisation with a memory. London: Department of Health, 2001

10 Schuster MA, McGlynn EA, Brook RH. How good is the quality of health care in the United States? Milbank Quarterly 1998;76:517-63.

11 Allen C, Glasziou P, Del Mar. Lancet 1999:354:1229-33.

12 Kanavos P. Economy and finance: a prospective view of the financing of health care. Policy Futures for UK Health, Technical Series no 5, 1999.

13 Aiken LH, Clarke SP, Sloane DM, et al. Nurses' reports on hospital care in five countries. Health Aff $2001 ; 20: 43-53$

14 Amalberti $\mathbf{R}$. The paradoxes of almost totally safe transportation systems. Safety Sci 2000; 1-18.

15 Amalberti $\mathbf{R}$. The paradoxes of almost totally safe transportation systems. Saf Sci 2001;37:109-26.

16 Chassin MR. Assessing strategies for quality improvement. Health Aff 1997:16:151-61.

17 Balas EA, Boren SA. Managing clinical knowledge for health care improvement. Yearbook of Medical Informatics; Bethesda, MD: National Library of Medicine, 2000: 65-70.

18 Mainous AG, Hueston WJ, Clark JR. Antibiotics and upper respiratory infection: do some folks think there is a cure for the common cold? J Fam Pract 1996:42:357-6.

19 Gonzales R, Steiner JF, Sande MA. Antibiotic prescribing for adults with colds, upper respiratory tract infections and bronchitis by ambulatory care physicians. JAMA 1997;278:901-4.

20 Nyquist A, Gonzales R, Steiner JF, et al. Antibiotic prescribing for children with colds, upper respiratory tract infections, and bronchitis. JAMA 1998;279:875-7. 
21 Brook RH, McGlynn EA, Shekelle PG. Defining and measuring quality of care: a perspective from US researchers. Int J Qual Health Care 2000;1 2:281-95.

22 Enthoven A. In pursuit of improving the National Health Service. London: The Nuffield Trust, 1999.

23 McGlynn E, Brook RH. Keeping quality on the policy agenda. Health Aff 2001;20:82-90

24 Greco PJ, Eisenberg JM. Changing physicians' practices. N Engl J Med 1993;329:1271-3

25 Cabana MD, Rand CS, Powe NR, et al. Why don't physicians follow clinical practice guidelines? A framework for improvement. JAMA 1999;282:1458-65

26 Hayward RS. Clinical practice guidelines on trial. Can Med Assoc J 1997:156:1725-7

27 Lomas J, Anderson GM, Domnick-Pierre K, et al. Do practice guidelines guide practice? The effect of a consensus statement on the practice of physicians. N Engl J Med 1989;321:1306-11.

28 Reuters. Health headline. 18 May 2001

29 Chassin MR. Is health care ready for six sigma quality? Milbank Quarterly 1998;76:565-95.
30 Coulter A. Patient engagement. Invited paper for the US/UK collaboration meeting collaboration meeting

31 Shortell SM, Bennett CL, Bych GR. Assessing the impact of continuous quality improvement on clinical practice: what it will take to accelerate progress. Milbank Quarterly 1998;76:593-24.

32 Marshall $M$, Shekelle $P$, Leatherman $S$, et al. What do we expect to gain from the public release of performance data? A review of the evidence. JAMA 2000;283:1866-74.

33 Leatherman S, Sutherland K. Evolving quality in the NHS: policy, progress and pragmatic considerations. Qual Health Care 1998:7(Suppl):54-61

34 Blumenthal D, Kilo CM. A report card on continuous quality improvement. Milbank Quarterly 1998;76:625-48.

35 OECD. Health at a glance. Paris: OECD, 2001

36 Blumenthal D. Controlling health expenditures. N Engl J Med 2001;344:766-9

37 Hillman AL. Managing the physician: rules versus incentives. Health Aff 1991;10:138-46

38 Department of Health. The National Health Service plan for England: a plan for investment, a plan for reform. London: The Stationery Office, 2000. Also available at http://www.doh.gov.uk/nhsplan.

\section{Clinical Evidence-Call for contributors}

Clinical Evidence is a regularly updated evidence based journal available worldwide both as a paper version and on the internet. Clinical Evidence needs to recruit a number of new contributors. Contributors are health care professionals or epidemiologists with experience in evidence based medicine and the ability to write in a concise and structured way.

Currently, we are interested in finding contributors with an interest in the following clinical areas:

Altitude sickness; Autism; Basal cell carcinoma; Breast feeding; Carbon monoxide poisoning; Cervical cancer; Cystic fibrosis; Ectopic pregnancy; Grief/bereavement; Halitosis; Hodgkins disease; Infectious mononucleosis (glandular fever); Kidney stones; Malignant melanoma (metastatic); Mesothelioma; Myeloma; Ovarian cyst; Pancreatitis (acute); Pancreatitis (chronic); Polymyalgia rheumatica; Post-partum haemorrhage; Pulmonary embolism; Recurrent miscarriage; Repetitive strain injury; Scoliosis; Seasonal affective disorder; Squint; Systemic lupus erythematosus; Testicular cancer; Varicocele; Viral meningitis; Vitiligo

However, we are always looking for others, so do not let this list discourage you.

Being a contributor involves:

- Appraising the results of literature searches (performed by our Information Specialists) to identify high quality evidence for inclusion in the journal.

- Writing to a highly structured template (about 2000-3000 words), using evidence from selected studies, within 6-8 weeks of receiving the literature search results.

- Working with Clinical Evidence Editors to ensure that the text meets rigorous epidemiological and style standards.

- Updating the text every eight months to incorporate new evidence.

- Expanding the topic to include new questions once every 12-18 months.

If you would like to become a contributor for Clinical Evidence or require more information about what this involves please send your contact details and a copy of your CV, clearly stating the clinical area you are interested in, to Claire Folkes (cfolkes@bmigroup.com).

\section{Call for peer reviewers}

Clinical Evidence also needs to recruit a number of new peer reviewers specifically with an interest in the clinical areas stated above, and also others related to general practice. Peer reviewers are health care professionals or epidemiologists with experience in evidence based medicine. As a peer reviewer you would be asked for your views on the clinical relevance, validity, and accessibility of specific topics within the journal, and their usefulness to the intended audience (international generalists and health care professionals, possibly with limited statistical knowledge). Topics are usually 2000-3000 words in length and we would ask you to review between 2-5 topics per year. The peer review process takes place throughout the year, and our turnaround time for each review is ideally 10-14 days.

If you are interested in becoming a peer reviewer for Clinical Evidence, please complete the peer review questionnaire at www.clinicalevidence.com or contact Claire Folkes (cfolkes@bmigroup.com). 